\title{
High resolution land use map for eco-hydrological modelling from IACS/LPIS geodata conflation
}

\author{
Flavio Lupia ${ }^{\mathrm{a}^{*}}$, Davide Rizzi ${ }^{\mathrm{b}}$, Diego Gallinelli ${ }^{\mathrm{a}}$, Pietro Macedoni ${ }^{\mathrm{c}}$, Fabio Pierangeli ${ }^{\text {a }}$, Salvatore \\ Carfî $^{\mathrm{d}}$, Giuseppe Pulighe ${ }^{\mathrm{a}}$ \\ ${ }^{a}$ CREA-Centro di ricerca Politiche e Bioeconomia,Roma, Italy,flavio.lupia@crea.gov.it, giuseppe.pulighe@crea.gov.it, \\ diego.gallinelli@crea.gov.it,fabio.pierangeli@crea.gov.it \\ ${ }^{b}$ SIN S.p.A. - Sistema Informativo Nazionale per lo sviluppo dell'agricoltura, Roma, Italy, davide.rizzi@sin.it \\ ${ }^{c}$ Alma Mater Studiorum - University of Bologna, Bologna, Italy, pietro.macedoni@gmail.com \\ ${ }^{d}$ AGEA - Agenzia per le Erogazioni in Agricoltura, Roma, Italy, s.carfi@agea.gov.it \\ * Corresponding author
}

Keywords: geospatial data, administrative data, SWAT, land use/cover map, Puglia

\begin{abstract}
:
Eco-hydrological models, such as SWAT (Soil Water Assessment Tool), are used to simulate complex hydrological processes and LU management in relation to water quality and quantity on a wide range of ecosystems. SWAT, developed by United States Department of Agriculture, is one of the most widely used watershed-scale modelling to assess changes in landscape management practices on water, sediment, and chemical yield. However, the availability of LU maps with good spatial and thematic resolution is one of the limiting factors in watershed modelling. Updated and detailed LU maps are required to grasp the variability and complexity of modelled landscapes. In fact, detailed LU maps with crop types can improve the model's capabilities in simulating evapotranspiration, surface runoff, soil infiltration, nutrient loss, and biomass production.
\end{abstract}

This work reports the achievements in developing an integrated LU map for modelling watershed processes in the Mediterranean context within the Cervaro river basin (900 sq. km ca.), South Italy (Puglia region), with a dominant agricultural LU (Figure 1). Water is a critical natural resource in a Mediterranean country like Italy, vulnerable to risks stemming from climate change such as a related risk of decrease in water availability and crop yields.

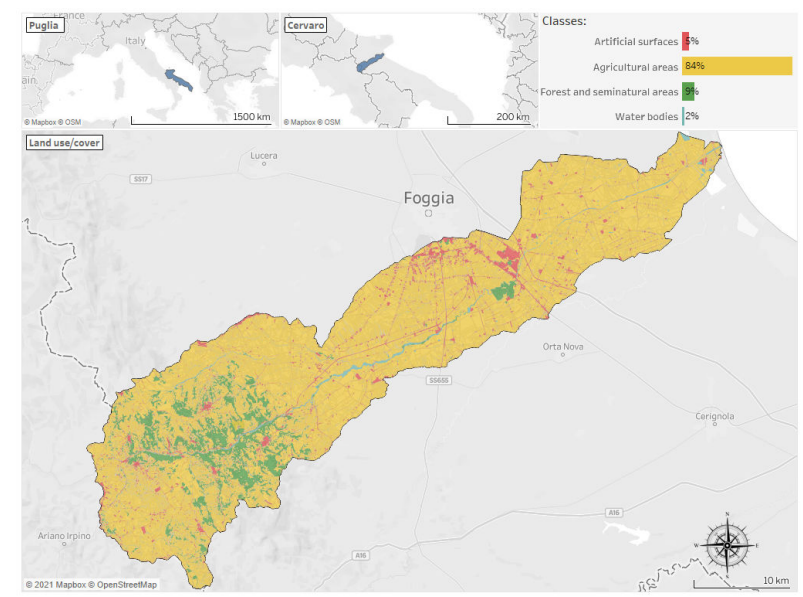

Figure 1. The land use map of the Cervaro basin created through the integration of IACS vector geodata.

We applied a methodology for geospatial data integration from the Italian Paying Agency (AGEA) responsible for managing the farmers' subsidies with the Integrated Administration and Control System (IACS) in the framework of the Common Agricultural Policy (CAP). IACS geodata, such as the Land Parcel Identification System (LPIS) and the GeoSpatial Aid Application (GSAA), are the relevant resource on LU parcels managed by Italian farms. This typology of data is one of the best maintained datasets in EU with regular updates and quality controls. Recently, IACS data reusability is becoming a reality thanks to effort of the EU Commission to opening the data within the more general action in "shaping Europe's digital future" by fostering the re-use of government-held data (Directive (EU) 2019/1024). LPIS contains homogeneous land use/cover areas digitized from ortho-imagery with high spatial resolution, resulting in a wall-to-wall map including Italian agricultural and non-agricultural areas with a full update every three years. GSAA 
contains digitized on-screen parcels for which an aid is requested yearly by Italian farmers and modified/updated by the paying agency after controls to ensure accuracy. Thematic details on agriculture within GSAA is dramatically higher than the LPIS thanks to the availability of crops classes detailed with a 5-level nomenclature. Within the LPIS an additional geographical layer is also available reporting the cadastral parcels with updated LU information deriving from in-situ field checks and other administrative sources.

The conflation method for integrating the three vector layers (two LPIS and GSAA) followed different steps: conversion to a common projection system, topology and geometry checks, aggregation of small polygons and nomenclatures matching (from IACS to SWAT classes) through semantic analysis. Geometric and attributes processing allowed to reduce dimensionality of the "hybrid layer": from 300k to 50k ca. polygons and from $33 \mathrm{k}$ LU combinations to 57 SWAT LU classes (Table 1).

\begin{tabular}{|c|c|c|c|c|c|}
\hline LU classes & $\begin{array}{l}\text { No. of } \\
\text { SWAT } \\
\text { classes }\end{array}$ & SWAT classes & $\begin{array}{l}\text { No. of } \\
\text { features }\end{array}$ & $\begin{array}{l}\text { Area } \\
\left(\mathbf{K m}^{2}\right)\end{array}$ & $\begin{array}{l}\text { Area } \\
(\%)\end{array}$ \\
\hline $\begin{array}{l}\text { Artificial } \\
\text { surfaces }\end{array}$ & 5 & $\begin{array}{l}\text { industrial; institutional; residen_high_den; residen_low_den; } \\
\text { transportation }\end{array}$ & 4675 & 45,68 & 5,1 \\
\hline $\begin{array}{l}\text { Agricultural } \\
\text { areas }\end{array}$ & 45 & $\begin{array}{l}\text { agrc; agrl; alfa; almd; appl; aspr; barl; broc; cabg; cant; cauf; } \\
\text { clva; corn; crgr; crrt; crwo; cucm; dwht; eggp; flax; fpea; grap; } \\
\text { gras; grbn; grsg; hay; oats; oliv; onio; orcd; past; pepr; pmil; } \\
\text { pota; radi; rnge; soyb; spin; sunf; swht; tobc; toma; trit; waln; } \\
\text { will[1] }\end{array}$ & 37494 & 753,27 & 83,9 \\
\hline $\begin{array}{l}\text { Forest and } \\
\text { seminatural } \\
\text { areas }\end{array}$ & 6 & barr; foen; frsd; frse; frst; rngb_test ${ }^{[2]}$ & 5928 & 83,86 & 9,3 \\
\hline Water bodies & 1 & watr $^{[3]}$ & 1468 & 14,91 & 1,7 \\
\hline Total & 57 & - & 49565 & 897,71 & 100 \\
\hline
\end{tabular}

Table 1. SWAT land use/cover classes and subclasses by number of features and areal extension for the Cervaro basin.

The "hybrid layer" (Figure 2) enables accurate modelling with SWAT to understand the relationship between LU management and water quality as an important opportunity in the context of both the reformed CAP and the Farm to Fork strategy aiming to reduce the environmental and climate footprint of the EU food system by preserving and restoring the land and freshwater resources. The spatial details coming from very high-resolution imagery and thematic details enhanced by administrative controls and farmers declarations provides much higher performances compared to classical LU maps. The EU-wide data availability, the yearly updates of information and the detailed attributes (e.g., crops typology, greening and organic practices, crop rotation, conservation tillage, etc.) can shift upward the accuracy of the eco-hydrological modelling.

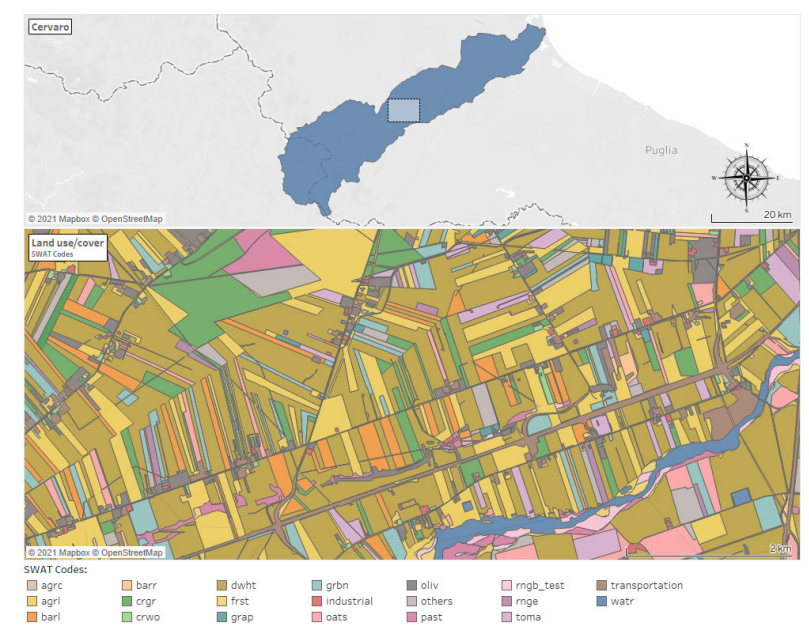

Figure 2. Thematic and spatial detail of the "hybrid layer". 